\section{Gespräche mit Kalypso. Über die Musik (1910)}

In Döblins erster ästhetischer Schrift, die 1910 in der Zeitschrift Der Sturm erschien, tritt der experimentelle Charakter besonders deutlich hervor. Die Gespräche mit Kalypso. Über die Musik bieten Ästhetik in dramatisch-dialogischer Form und stehen damit auf der Scheidelinie zwischen fiktionaler Literatur und theoretischer Reflexion. Performativ setzen sie die Spannung zwischen sinnlich-anschaulichem und theoretischem Denken in Szene. In ihrer gattungsmischenden Verfahrensweise schließen sie an die Tradition der Frühromantik an, ebenso in ihrem Bestreben, naturwissenschaftliche, philosophische und ästhetische Ideen miteinander zu verbinden. Das eklektizistische Verfahren, das sich auf der Ebene von Handlung und Motiven als Synkretismus archaischer und moderner Elemente realisiert, ist Ausdruck eines Denkens »in offenen Relationen statt in festen Hierarchien " (Kuttnig 1993, 205). Dies ist charakteristisch für Döblin, der auch in seinen späteren theoretischen Schriften bestrebt ist, unterschiedliche Denkimpulse aufzunehmen und zusammenzuführen.

Auf der griechischen Insel Ogygia verwickelt die Göttin Kalypso (eine intertextuelle Referenz auf die Odyssee) einen gestrandeten, in ihrer Gewalt befindlichen Musiker in einen Diskurs über Musik und Töne. Das Gespräch der beiden, das sich im Wechselspiel von Distanzierung und Annäherung vollzieht, liefert Bausteine für eine Musikästhetik, die sich in eigenwilliger Unabhängigkeit von zeitgenössischen musiktheoretischen Ansätzen und im Rückgriff auf die romantische Idee von der Absolutheit der Musik entfaltet. Zugleich dienen diese Überlegungen als Sprungbrett für eine grundsätzliche Auseinandersetzung mit dem Zeichencharakter der Künste, die auf die Sprache ausgeweitet wird. In den Mittelpunkt rückt dabei die Frage, ob die Möglichkeiten der Kunst dem Leben überhaupt gewachsen sind oder ob sie, so Kalypsos Vorwurf, jämmerlich vor ihm versagen müssen. Die semiotischen Überlegungen zur Sprache zielen auf die Arbitrarität von Signifikant und Signifikat und erkennen auf dieser Grundlage der Sprache das mimetische Vermögen ab; Sprache, so die Folgerung, habe »nichts mit dem gemeinsam, das sie bezeichnet« (SÄPL 57). Die Gespräche mit Kalypso suchen daher für die Kunst nach einem dritten Weg zwischen Mimesis und selbstzweckhaftem Spiel, zwischen Naturalismus und Ästhetizismus (Braungart 1995, 293). Dabei scheint das
Ideal einer Kunst auf, die Leben nicht abbildet, sondern selbst Lebensvollzug ist: »Es könnte eine Musik geben, die jedes Zeichenwertes bar abrollte und Geschehen selbst wäre (SÄPL 91).

Bedeutend sind die Gespräche mit Kalypso nicht allein als ein Beitrag zur Musiktheorie, sondern vor allem als Versuch der künstlerischen Selbstbegründung (Balve 1990, 17 f.). Gleich diese erste ästhetische Schrift rückt die Aspekte ins Zentrum, um die Döblins theoretische Reflexion fortan kreist: das Verhältnis von Kunst und Realität, die Voraussetzungen und das Wesen des schöpferischen Gestaltungsprozesses, die Rolle des Künstler-Ichs, dem die Gespräche mit Kalypso nachdrücklich einen Ort im Leben zuweisen: »Der Künstler ist in der Welt, ein Teilchen der Welt; sein wunschvollstes Sinnen und Sehnen durchbricht diese Welt nicht; es ist derselbe Mensch, der lebt, ißt, trinkt, sich müht und lacht« (SÄPL 59). 